Revista Eletrônica em Gestão, Educação e Tecnologia Ambiental Santa Maria, v. 20, n. 1, jan.-abr. 2016, p. 552-565

Revista do Centro de Ciências Naturais e Exatas - UFSM

ISSN : 22361170

\title{
Uso do índice RDE para determinação de anomalias de drenagem no Rio Capibaribe (PE)
}

\author{
Rubens Neves e Silva ${ }^{1}$, Daniel Dantas Moreira Gomes ${ }^{2}$, Carlos Eduardo Santos de Lima ${ }^{3}$ e \\ Mauricio Costa Goldfarb ${ }^{4}$ \\ 1,3 Universidade de Pernambuco (UPE) - Campus Garanhuns, Brasil \\ 2,4 Prof. Dr. da Universidade de Pernambuco (UPE)-Campus Garanhuns, Brasil
}

\begin{abstract}
Resumo
O perfil longitudinal de um rio é a representação cartesiana da relação entre sua altitude e o seu comprimento. Esta relação tem sido usada como importante elemento para estudos geomorfológicos e hidrológicos; a exemplo dos estudos para determinação das anomalias de drenagem. Este trabalho teve como objetivo a determinação e classificações das anomalias de drenagem do Rio Capibaribe (PE). A análise foi feita a partir do perfil longitudinal do Rio Capibaribe, construído com o auxílio do software Google Earth, através do índice RDE proposto por Hack (1973). O perfil longitudinal do Rio Capibaribe encontra-se relativamente equilibrado, apresentando ainda anomalias de $2^{a}$ e $1^{a}$ ordem. Tal perfil apresentou uma geometria atípica nos trechos entre os quilômetros 100 e 150, 150 e 200 e 200 e 250 em decorrência do aumento das declividades no sentido de montante para jusante, visto que a literatura indica que em um perfil típico as declividades devem diminuir no sentido da foz.
\end{abstract}

Palavras-chave: Rio Capibaribe. Perfil Longitudinal. Índice RDE. Anomalias de Drenagem.

\begin{abstract}
The longitudinal profile of a river is the Cartesian representation of the relationship between its height and its length. This relationship has been used as an important element for geomorphological and hydrological studies; example studies to determine the drainage anomalies. This study aimed to the determination and classification of river Capibaribe (PE) drainage anomalies. The analysis was made from the longitudinal profile of the Capibaribe river, built with the help of Google Earth software, through the RDE index proposed by Hack (1973). The longitudinal profile of the Capibaribe river is relatively balanced and contains anomalies second and first order. This profile presented an atypical geometry stretches in between kilometers 100 and 150, 150 and 200 and 200 and 250 due to the increase of the slope in the direction from upstream to downstream, as the literature indicates that in a typical profile should decrease in the slopes towards the mouth.
\end{abstract}

Keywords: Capibaribe river, longitudinal profile, RDE index, drainage anomalies. 
Silva et al.: Uso do índice RDE para determinação de anomalias de drenagem...

\section{Introdução}

Representado no plano cartesiano, o perfil longitudinal de um rio descreve a relação existente entre a variação altimétrica e o comprimento do mesmo desde a nascente até a foz ou até a convergência com um outro rio. De acordo com Knighton (1998) apud Nery (2010), o perfil longitudinal consiste num método simples e eficaz, que utiliza-se de dados de altitude e extensão do canal. Quando aliado a estudos de hidrologia e geomorfologia, o perfil longitudinal de um rio pode ser uma ferramenta muito importante por facilitar à compreensão dos condicionantes que equilibram ou desequilibram o sistema fluvial; possibilitando a compreensão de diversos fenômenos hidrológicos em uma bacia hidrográfica.

Os estudos sobre perfil longitudinal de rios principiam na Europa, em meados do século XIX, influenciados pela necessidade da navegação fluvial. Segundo Guedes (2011), no Brasil, Alfredo Bjorneg, no final dos anos 60, foi pioneiro em estudos flúvio-morfométricos com construções de perfis longitudinais de drenagens. Guedes (op. cit), afirma ainda que diversos autores realizaram pesquisas utilizando perfis longitudinais de drenagens, a exemplo dos trabalhos desenvolvidos na região amazônica por Rodriguez \& Suguio (1992); na bacia hidrográfica do Rio do Peixe, no oeste paulista (Etchebehere \& Saad, 1999); na bacia do rio Santo Anastácio (Santoni et al, 2004). Inclusive em bacias do estado de Pernambuco, como no caso da bacia do Rio Una com a utilização de cartas topográficas (Melo \& Goldfarb, 2012); também na bacia do Una, porém utilizando-se o software Google Earth (Souza et al, 2011).

A construção do perfil longitudinal é comumente feita com dados obtidos de cartas topográficas ou mesmo a partir de dados obtidos diretamente do trabalho de campo. No entanto a tecnologia tem contribuído significativamente para realização de pesquisas nessa área. Conforme Santos \& Segantine (2006) apud Silva \& Nazareno (2009) os recursos tecnológicos disponíveis à cartografia têm viabilizado avanços consideravelmente importantes, através, principalmente, dos softwares que permitem velocidade na obtenção de dados, na troca de informações espaciais e em sofisticadas análises dos fenômenos espaciais. Amaral \& Rosalen (2009) em pesquisa comparativa conclui que o software Google Earth ${ }^{\circledR}$ é mais exato e preciso do que o GPS e eclímetro na determinação da declividade, e também é adequado para fins de classificação do relevo e da capacidade de uso da terra entre outras aplicações. Segundo Rocha (2007) apud Nery (2010), o uso das imagens de sensoriamento remoto tem se multiplicado devido à evolução dos sensores, com resoluções cada vez melhores, associadas às técnicas de extração das informações advindas do processamento dessas imagens.

O uso do Google Earth para determinação de perfil longitudinal já tem sido desenvolvido, a exemplo do trabalho apresentado por Souza et al (2011), que constrói o perfil do Rio Una. Posteriormente, Melo \& Goldfarb (2012), a partir de métodos tradicionais, ou seja, com uso de cartas topográficas, reconstroem o perfil do Rio Una e fazem uma comparação a partir da sobreposição com o perfil de Souza et al. (2011); estes autores observam a grande similaridade entre as curvas, e portanto contribuem para a validação da possibilidade do uso do Google Earth para determinação de perfis longitudinais.

Este trabalho visa construir o Perfil Longitudinal do curso principal da Bacia do Rio Capibaribe, utilizando o software Google Earth em sua versão gratuita e fazer sua análise através do índice RDE, para detecção de possíveis trechos anômalos, buscando detalhar os trechos anômalos nos seus respectivos municípios e aferir sobre os principais elementos que contribuem para sua existência.

\section{Metodologia}

\section{1 Área de Estudo}

A Unidade de Planejamento Hídrico UP2, que corresponde à bacia hidrográfica do Rio Capibaribe, está localizada na porção norte-oriental do Estado de Pernambuco, entre os paralelos $07^{\circ} 41^{\prime} 20^{\prime \prime}$ e $08^{\circ}$ $19^{\prime} 30^{\prime \prime}$ de latitude sul e os meridianos $34^{\circ} 51^{\prime} 00^{\prime \prime}$ e $36^{\circ} 41^{\prime} 58^{\prime \prime}$ de longitude oeste, limitando-se ao norte com o Estado da Paraíba, a bacia do Rio Goiana (UP1) e grupo de pequenos rios litorâneos 1 GL1 (UP14), ao sul com a bacia do Rio Ipojuca (UP3) e o grupo de bacias de pequenos rios litorâneos 2 
- GL2 (UP15), a leste com o Oceano Atlântico e os grupos GL1 e GL2, a oeste, com o Estado da Paraíba e a bacia do Rio Ipojuca (Agência Pernambucana de Águas e Climas (APAC, 2014)).

Conforme a Secretaria de Recursos Hídricos do Estado de Pernambuco (SRH, 2010) a área da bacia é de 7.454,88 km2, ou seja, 7,58\% do território Pernambucano. Desde sua nascente, entre os municípios de Poção e Jataúba, à sua foz, no Recife, cortando 42 municípios, dos quais 15 estão totalmente inseridos na bacia e 26 possuem sua sede na bacia (Pernambuco, 2006). A figura 1 mostra a localização da bacia do rio Capibaribe e os municípios que fazem parte da bacia.

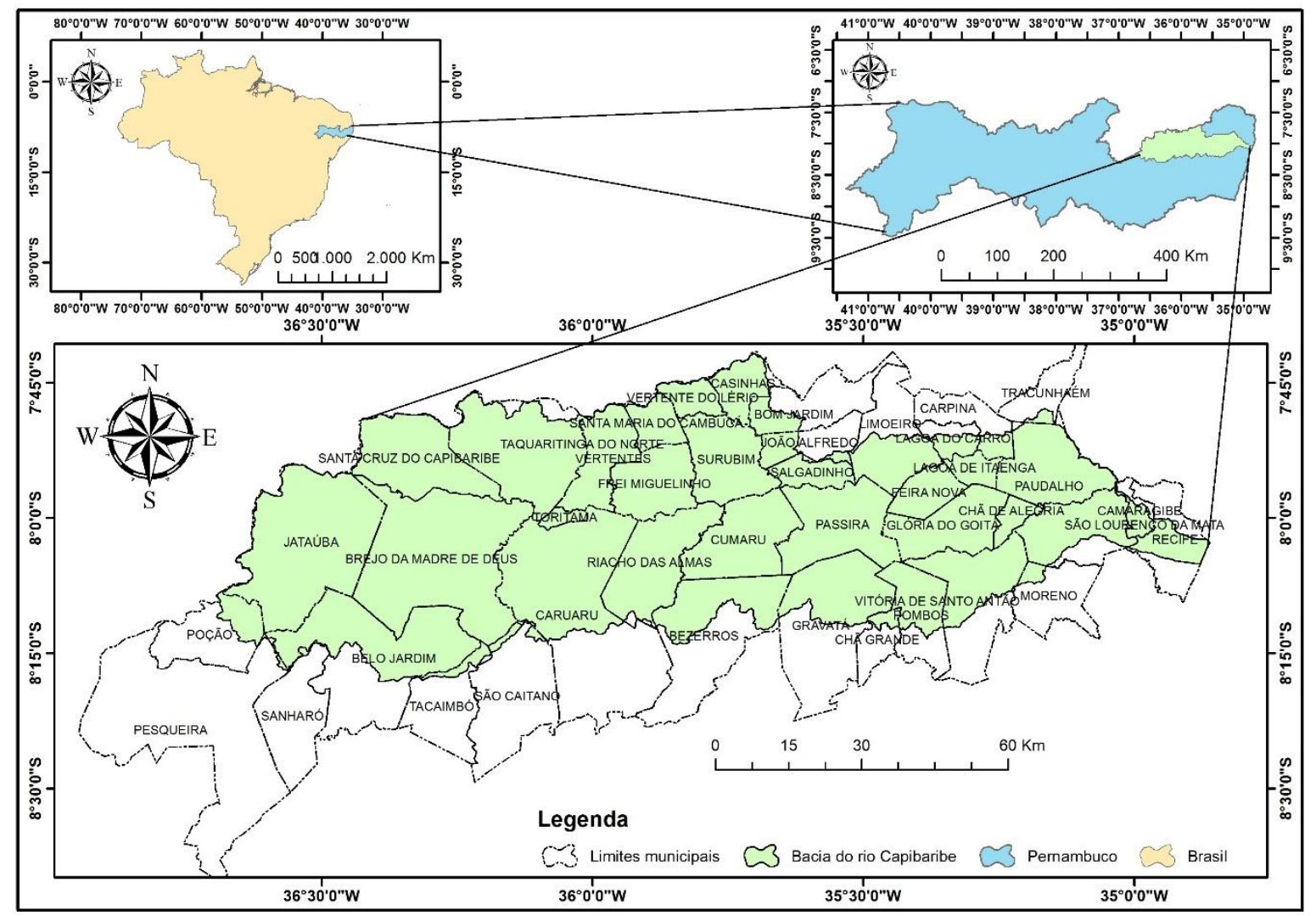

Figura 1 - Localização da bacia hidrográfica do Rio Capibaribe

Fonte: Fonte: Cartas SRTM EMBRAPA (Brasil em Relevo), Base Cartográfica IBGE. Adaptado por Silva, R. N. no ArcGis

Segundo Andrade (2007), juntamente com os Rios Una e Ipojuca, o Capibaribe compõe o grupo dos três rios mais importantes do Estado de Pernambuco. Esse rio abastece 43 municípios e 3.474.198 habitantes, dos quais 87,2\% residem especialmente na zona urbana da Região Metropolitana do Recife (SRH/CPRH, 2002 apud Souza, 2011), ou seja, esse rio abastece cerca de $43 \%$ da população pernambucana.

De acordo com a APAC (2014) o curso principal do Capibaribe apresenta extensão total de cerca de $280 \mathrm{~km}$, possuindo regime fluvial intermitente nos seus alto e médio cursos, tornando-se perene somente a partir do município de Limoeiro, no seu baixo curso. Seus principais afluentes pela margem direita (são): Riacho do Mimoso, Riacho Tabocas, Riacho da Onça, Riacho Carapatós, Riacho das Éguas, Riacho Caçatuba, Riacho Batatã, Rio Cotungubá, Rio Goitá e Rio Tapacurá. Pela margem esquerda, destacam-se: Riacho Jataúba, Riacho Doce, Riacho Topada, Riacho do Manso e Riacho Cajaí. A figura 2 apresenta o curso principal da bacia hidrográfica do Rio Capibaribe e seus principais afluentes. 


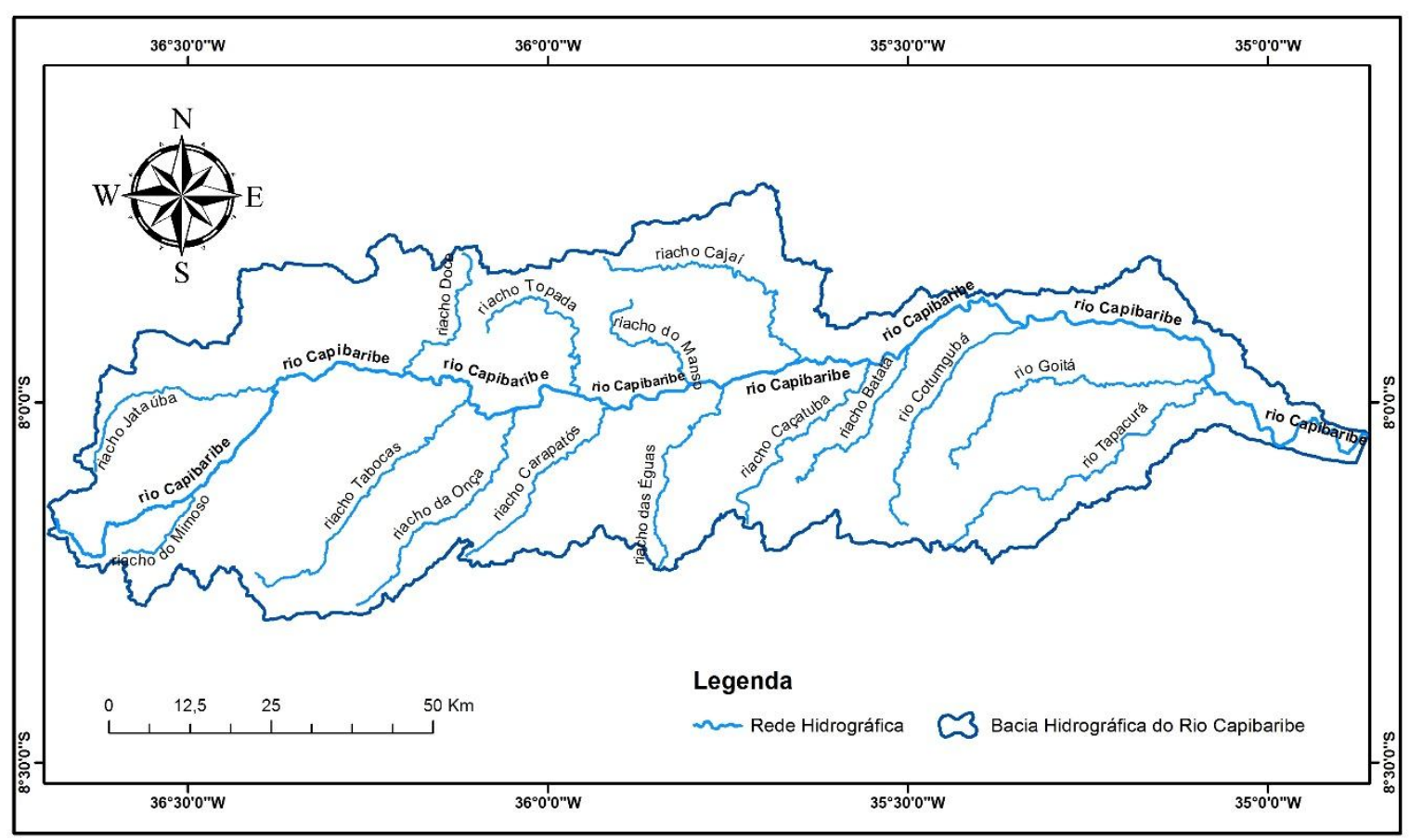

Figura 2 - Curso principal da bacia hidrográfica do Rio Capibaribe e seus principais afluentes. Fonte: Cartas SRTM EMBRAPA (Brasil em Relevo). Adaptado por Silva, R. N. no ArcGis

A bacia do Rio Capibaribe tem causado inundações históricas, especialmente em seu médio e baixo curso, atingindo a capital e outras cidades ribeirinhas do médio e baixo curso do rio. Ao longo do tempo, foram adotadas medidas para solucionar o problema, principalmente após a cheia de 1975. A construção de barragens para o controle de cheias reduziu significativamente os efeitos das enchentes, porém a possibilidade de extravasamento da calha do rio ainda persiste (SRH, 2010).

Ao longo do seu percurso o Rio Capibaribe tem como principais reservatórios: Jucazinho $\left(327.035 .818 \mathrm{~m}^{3}\right)$, Carpina $\left(270.000 .000 \mathrm{~m}^{3}\right)$, Tapacurá $\left(94.200 .000 \mathrm{~m}^{3}\right)$, Goitá $\left(52.000 .000 \mathrm{~m}^{3}\right)$, Poço Fundo $\left(27.750 .000 \mathrm{~m}^{3}\right)$, Eng. Cercino Pontes $\left(13.600 .000 \mathrm{~m}^{3}\right)$, Cursaí $\left(13.000 .000 \mathrm{~m}^{3}\right)$, Várzea do Una $\left(11.568 .010 \mathrm{~m}^{3}\right)$, Machado $\left(6.800 .000 \mathrm{~m}^{3}\right)$, Oitis $\left(3.020 .159 \mathrm{~m}^{3}\right)$, Mateus Vieira $\left(2.752 .000 \mathrm{~m}^{3}\right)$, Matriz da Luz $\left(1.250 .000 \mathrm{~m}^{3}\right)$ e Sítio Piaça $\left(1.167 .924 \mathrm{~m}^{3}\right)$.

\subsection{Perfil Longitudinal}

O perfil longitudinal de um rio está intimamente ligado ao relevo, pois descreve a relação entre altitude e extensão ao longo do canal fluvial. Consiste basicamente em um gráfico cartesiano capaz de representar um rio em duas dimensões, ou seja, em termos de altitude para o eixo das ordenadas e extensão para o eixo das abscissas, sendo assim constitui-se em um método muito prático para visualização e análise da declividade ou gradiente altimétrico de um curso d'água. Hack (1973) afirma que a análise de perfis longitudinais de drenagem constitui um método simples para análise de terrenos fornecendo indicativos sobre condições do substrato rochoso entre outros fatores que determinam a morfologia do terreno.

Segundo Cunha, (1996) apud Melo et al. (2009) o perfil longitudinal de um rio sofre contínuas alterações, devido às variações no escoamento e na carga sólida, o que acarreta muitas irregularidades no seu leito como as corredeiras e as depressões. Ao longo do canal, o rio tenta eliminar essas irregularidades, na tentativa de adquirir um perfil longitudinal côncavo e liso, com declividade suficiente para transportar a sua carga. Alguns fatores influenciam no perfil longitudinal tais como a confluência de tributários, ausência de vegetação, as variações na resistência à erosão do substrato rochoso, a erosão remontante por mudança brusca em nível à jusante ou ainda as deformações neotectônicas locais na bacia de drenagem (Acklas Jr. R. et al., 2003) apud Melo et al. (2009). 
Christofoletti (1980) ao discorrer sobre a influência de rios tributários em alterações na forma do perfil longitudinal de um rio principal afirma que esta influência varia conforme a carga detritica e o débito. Já no que diz respeito a influência da vegetação Hack (1973) salienta que a largura do canal pode aumentar a taxas diferentes em áreas áridas e áreas úmidas e dessa forma constituindo um elemento influenciador da declividade assim como o clima.

Normalmente, os rios ao longo de seu curso possuem vários trechos em equilíbrio (ajustados) e em desequilíbrio (desajustados). Neste contexto, Carlston (1969) apud Melo et al. (2009) ressalta que os trechos em equilíbrio apresentam inclinações suaves e decrescentes no sentido de montante para jusante, já os trechos em desajustes apresentam irregularidades ou mesmo deformações em seu traçado, compreendidas como anomalias de drenagem.

\subsection{Anomalias de drenagem}

O perfil longitudinal padrão tem sido comumente proposto na literatura como parâmetro de referência para perfis longitudinais reais estudados. Apesar de não haver consenso, de uma maneira geral, tem sido aceita como perfil padrão uma curva suave disposta no plano cartesiano com concavidade voltada para cima, de ajuste geralmente exponencial, e com declividade que diminui de forma gradual no sentido de montante para jusante. No entanto, conforme Lima (2013), a declividade geral de um perfil convencional padrão, por sua vez, é praticamente irreal e geomorfologicamente quase impossível de ser observada. Comumente, os perfis reais apresentam trechos com cotas superiores as que seriam de um perfil padrão, denominados trechos de soerguimento, assim como, trechos com cotas inferiores, denominados trechos de subsidência; nos dois casos, estas ocorrências estão associadas ao fenômeno conhecido como anomalias de drenagem, detectadas a partir da análise do perfil longitudinal.

Nesse mesmo sentido, Christofoletti (1980), ressalta que o perfil típico apresenta uma curva parabólica côncava com declividades maiores em direção à nascente e menores em direção à desembocadura. Os cursos d'água que apresentam essa morfologia são considerados em equilíbrio (igualdade entre a atuação da erosão, do transporte e da deposição). Ainda segundo Christofoletti (1980), o equilíbrio decorre em função das grandes cheias, à medida que o rio atinge o seu maior poder de abrasão em consequência da elevada carga detritica recebida.

As anomalias de drenagem representam desajustes conquanto ao perfil típico e podem ser classificadas como anomalias de $1^{\text {a }}$ ou $2^{a}$ ordem. As anomalias de $1^{a}$ ordem representam desajustes mais acentuados enquanto as anomalias de $2^{a}$ ordem apresentam os desajustes mais suaves ao longo do perfil. Tais anomalias podem comprometer os processos de erosão, transporte e deposição de sedimentos, além de, influenciar no escoamento superficial, pois, conforme afirma Christofoletti (1980), a velocidade das águas e a granulometria dos sedimentos componentes da carga do leito variam de acordo com os declives.

Diversas outras pesquisas têm tratado das anomalias de drenagem, a exemplo de Snow \& Slingerland (1987), que a partir da aplicação de modelos matemáticos, correlacionam as anomalias de drenagem ao transporte de sedimento, entre outros, função da composição do material do leito. De forma geral, diversos elementos podem contribuir para formação de anomalias de drenagem, a exemplo da composição geológica, de movimentos tectônicos, da confluência com rios tributários, e até elementos antrópicos que alterem a condição natural de transporte de sedimentos como a presença de barragens ou o desmatamento ciliar. Na literatura específica, a exemplo de Etchebehere et al. (2004), Guedes (2006), Melo et al. (2009), Souza \& Goldfarb (2011), entre outros, tem buscado investigar a presença de anomalias de drenagem a partir da análise da relação declividade e extensão, metodologia proposta por Hack (1973), denominada índice RDE.

\section{$2.4 \mathrm{O}$ índice de gradiente RDE (relação declividade vs extensão)}

Hack (1973) elaborou uma proposta de análise chamada de índice RDE (relação declividade vs extensão) também designada de Stream-Gradiente Índex ou simplesmente índice SL, relação Slope vs

REGET - V. 20, n. 1, jan.- abr. 2016, p.552-565 
Length (declive da drenagem ou de um determinado trecho desta vs extensão da drenagem ou de um trecho específico), aplicando esse índice para estudos referentes a neotectônica em vários contextos geológicos. Ele propôs este índice como um elemento bastante prático para a determinação de anomalias na concavidade natural do perfil longitudinal, o que possibilitou a normalização dos valores de gradiente e a identificação de anomalias de drenagem em cada trecho de seu curso (Melo, et al. 2009). De acordo com Lima (2013), o índice de gradiente é uma alternativa para a análise mais eficiente do controle exercido por fatores geológicos sobre o perfil longitudinal de um canal de drenagem, pois deriva do perfil semilogarítmico, o que evita o efeito da diminuição da declividade pelos fatores hidráulicos e sedimentológicos. As equações propostas Hack (op. cit) para cálculo do índice são:

$\begin{array}{rlrllll}\operatorname{RDE} & \text { trecho } & = & (\Delta \mathrm{H} & / & \Delta \mathrm{L}) & \mathrm{L} \\ \mathrm{RDE} & \text { total } & = & (\Delta \mathrm{H} & / & \mathrm{Log} & \mathrm{n})\end{array}$

(2)

Onde $\Delta \mathrm{H}$ é a diferença altimétrica entre dois pontos selecionados do curso d'água para a equação (1), já para a equação (2) a expressão $\Delta \mathrm{H}$ refere-se a diferença altimétrica total do canal, $\Delta \mathrm{L}$ é a projeção horizontal da extensão do referido segmento, L corresponde à extensão acumulada do rio até o ponto final do trecho onde o índice RDE está sendo calculado, Log n é o logaritmo natural da extensão total do canal.

Nesse estudo foram considerados os valores de RDE de cada trecho (razão entre RDE trecho/RDE total) como equilibrado no intervalo 0 a 2 e entre os limiares 2 a 10 correspondem à anomalias de $2^{\text {a }}$ ordem e, os valores de RDE acima de 10 correspondem à anomalias de $1^{\text {a }}$ ordem, conforme sugerido por Etchebehere (2000 apud Melo et al 2009).

\section{Resultados e discussão}

\subsection{Determinação do percurso}

Inicialmente foi demarcada a nascente do Rio Capibaribe como marco inicial da digitalização da rota, em seguida foi utilizada a função "Adicionar caminho" através da qual foi possível traçar o curso principal do rio obedecendo todo o contorno do seu leito, dividi-lo em trechos, além de determinar a extensão dos trechos e a extensão total do canal. Concomitantemente a construção do curso principal da bacia do rio, foram coletados dados de altitude ao final de cada trecho através da barra de status, para posteriormente construir seu perfil topográfico. A figura 3 mostra o curso principal do rio Capibaribe construído e representado no Google Earth. 


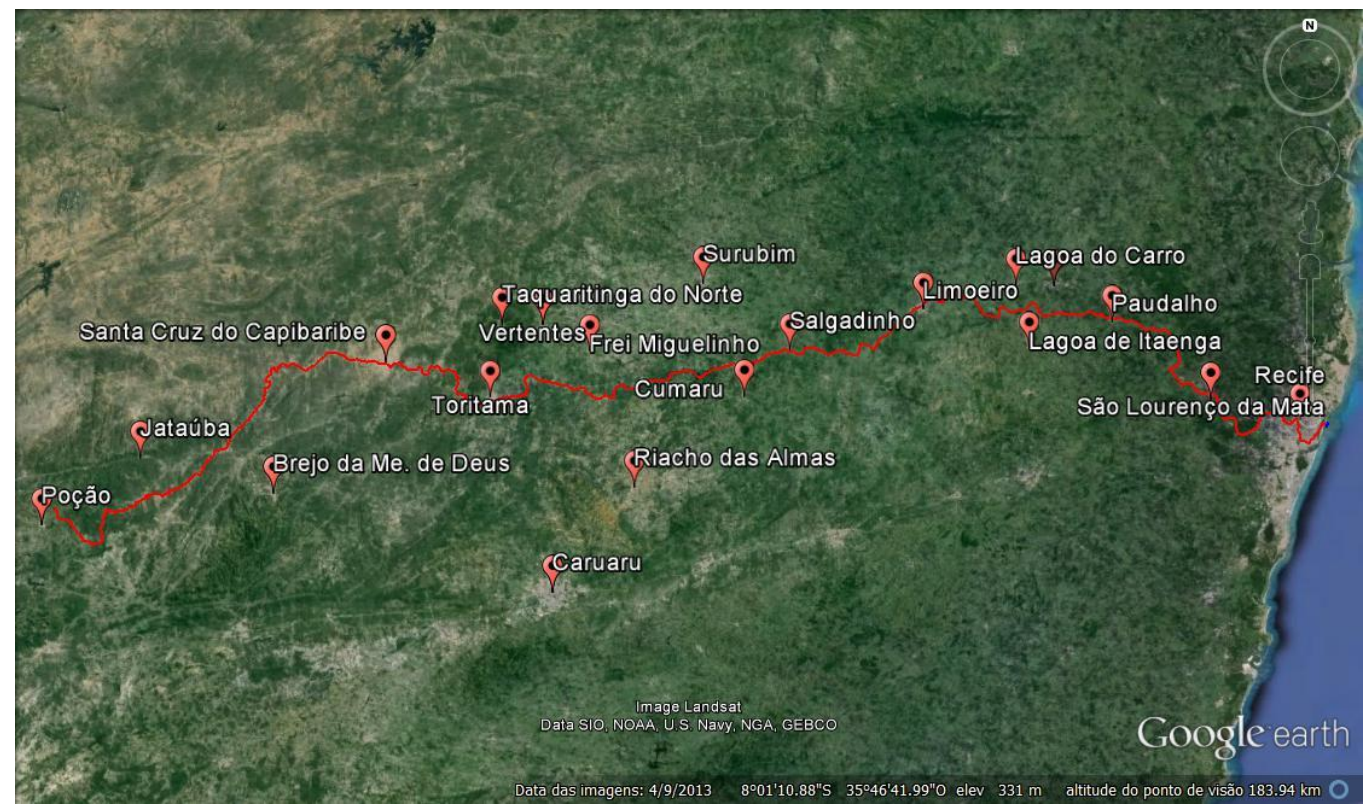

Figura 3 - Curso principal do Rio Capibaribe (PE)

Fonte: Google Earth (Data SIO, NOAA, U. S. Navy, NGA, GEBCO). Adaptado por Silva, R. N.

Para obter a figura 3 foi necessário distanciar o ponto de visão a uma altitude de 184,68 km, para ter uma visualização geral do percurso do Rio Capibaribe desde sua nascente nas proximidades da divisa entre os municípios de Poção e Jataúba; passando pelos municípios que são transpostos pelo rio, até sua foz no município de Recife.

\subsection{O perfil longitudinal do Rio Capibaribe}

O marco inicial de digitalização do curso principal do Rio Capibaribe foi sua nascente. A partir da sua nascente o percurso total foi dividido em trechos de $4 \mathrm{~km}$, com exceção do último trecho com 4,9 $\mathrm{km}$. Em cada um dos pontos delimitados pelos trechos foram coletados os seus respectivos dados de altitude. Dessa forma o gráfico do perfil longitudinal do Rio Capibaribe, foi construído com 75 pontos ou pares ordenados (extensão, altitude). Posteriormente os 75 pontos coletados no Google Earth foram lançados em uma planilha do Microsoft Excel, onde foi plotado o gráfico do perfil longitudinal do Rio Capibaribe que pode ser visualizado na Fig. 4.

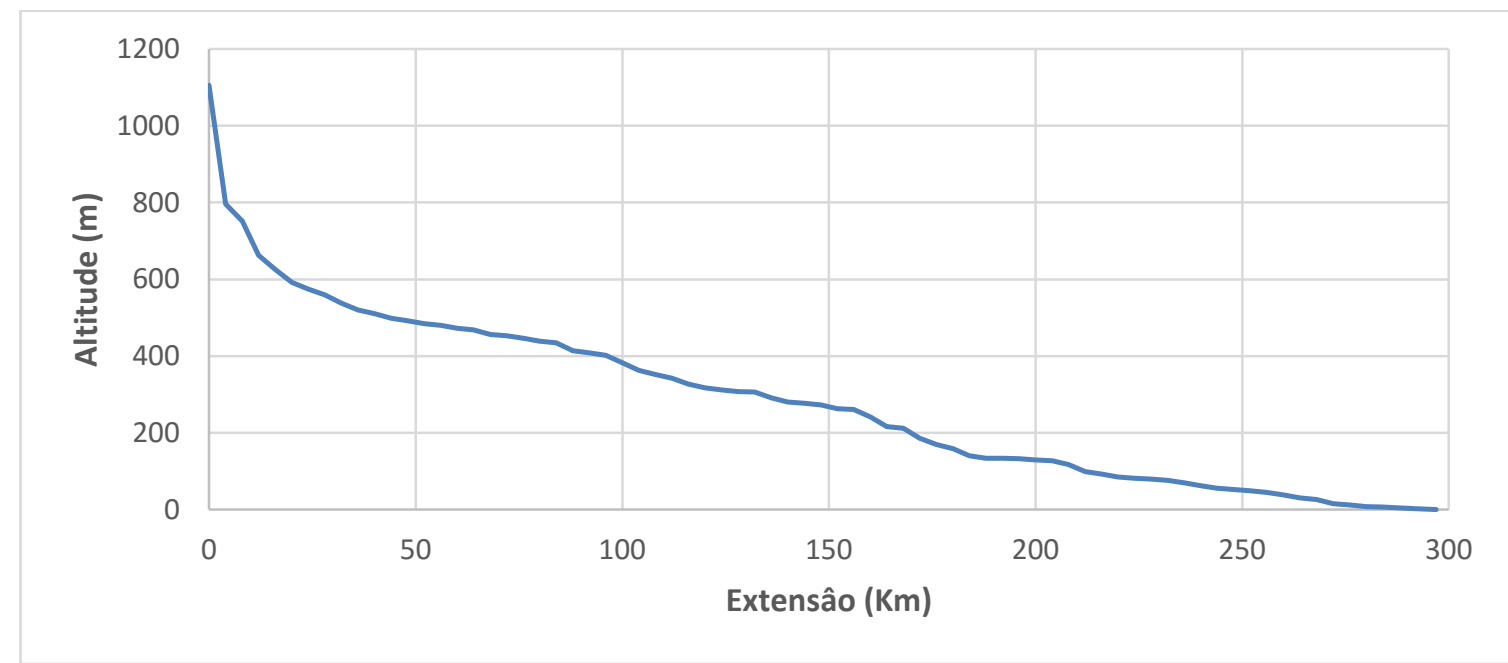

Figura 4 - Perfil longitudinal do rio Capibaribe

Fonte: Google Earth (dados). Adaptado por Silva R. N. em Microsoft Excel 2013. 
O perfil apresentado na figura 4 apresenta altitude de 1105 metros na sua nascente, extensão total de 296,9 km e declividade média de 3,72 metros por quilômetro. Nos trechos compreendidos, aproximadamente, entre os quilômetros 100 e 150, 150 e 200 e 200 e 250 observa-se uma geometria atípica do perfil longitudinal, em decorrência do aumento da declividade em direção a jusante nestes trechos; visto que a literatura indica que em um perfil típico a declividade deve diminuir no sentido da foz.

\subsection{Cálculo do Índice RDE}

Para cálculo do índice RDE, o curso principal do rio Capibaribe foi dividido em 73 trechos de $4 \mathrm{~km}$ e 1 trecho de 4,9 km. Os valores de RDE calculados em cada trecho do rio (de acordo com as equações 1 e 2 anteriormente apresentadas) são apresentados na tabela 1.

Tabela 1 - Resumo das variáveis morfométricas do rio Capibaribe

\begin{tabular}{|c|c|c|c|c|c|c|c|c|c|}
\hline Trecho & $\begin{array}{c}\text { Cota } \\
\text { Superior } \\
(\mathrm{m})\end{array}$ & $\begin{array}{l}\text { Cota } \\
\text { Inferior } \\
(\mathrm{m}) \\
\end{array}$ & $\begin{array}{c}\text { Diferença } \\
\text { altimétrica } \\
(\mathrm{m})\end{array}$ & $\begin{array}{c}\text { Extensão } \\
\text { doTrecho } \\
(\mathrm{km})\end{array}$ & $\begin{array}{c}\text { Extenção } \\
\text { total } \\
(\mathrm{km}) \\
\end{array}$ & $\begin{array}{c}\text { RDE } \\
\text { do } \\
\text { Trecho } \\
\end{array}$ & $\begin{array}{l}\text { RDE } \\
\text { Total }\end{array}$ & $\begin{array}{c}\text { RDE do } \\
\text { trecho/RDE } \\
\text { total }\end{array}$ & $\begin{array}{l}\text { Ordem da } \\
\text { Anomalia. }\end{array}$ \\
\hline 1 & 1105 & 796 & 309 & 4 & 4 & 309 & 87,69 & 3,52 & $2^{\mathrm{a}}$ ordem \\
\hline 2 & 796 & 751 & 45 & 4 & 8 & 90 & 87,69 & 1,03 & - \\
\hline 3 & 751 & 662 & 89 & 4 & 12 & 267 & 87,69 & 3,04 & $2^{\mathrm{a}}$ ordem \\
\hline 4 & 662 & 626 & 36 & 4 & 16 & 144 & 87,69 & 1,64 & - \\
\hline 5 & 626 & 592 & 34 & 4 & 20 & 170 & 87,69 & 1,94 & - \\
\hline 6 & 592 & 575 & 17 & 4 & 24 & 102 & 87,69 & 1,16 & - \\
\hline 7 & 575 & 559 & 16 & 4 & 28 & 112 & 87,69 & 1,28 & - \\
\hline 8 & 559 & 538 & 21 & 4 & 32 & 168 & 87,69 & 1,92 & - \\
\hline 9 & 538 & 520 & 18 & 4 & 36 & 162 & 87,69 & 1,85 & - \\
\hline 10 & 520 & 511 & 9 & 4 & 40 & 90 & 87,69 & 1,03 & - \\
\hline 11 & 511 & 499 & 12 & 4 & 44 & 132 & 87,69 & 1,51 & - \\
\hline 12 & 499 & 492 & 7 & 4 & 48 & 84 & 87,69 & 0,96 & - \\
\hline 13 & 492 & 485 & 7 & 4 & 52 & 91 & 87,69 & 1,04 & - \\
\hline 14 & 485 & 480 & 5 & 4 & 56 & 70 & 87,69 & 0,80 & - \\
\hline 15 & 480 & 473 & 7 & 4 & 60 & 105 & 87,69 & 1,20 & - \\
\hline 16 & 473 & 468 & 5 & 4 & 64 & 80 & 87,69 & 0,91 & - \\
\hline 17 & 468 & 456 & 12 & 4 & 68 & 204 & 87,69 & 2,33 & $2^{\mathrm{a}}$ ordem \\
\hline 18 & 456 & 453 & 3 & 4 & 72 & 54 & 87,69 & 0,62 & - \\
\hline 19 & 453 & 447 & 6 & 4 & 76 & 114 & 87,69 & 1,30 & - \\
\hline 20 & 447 & 439 & 8 & 4 & 80 & 160 & 87,69 & 1,82 & - \\
\hline 21 & 439 & 435 & 4 & 4 & 84 & 84 & 87,69 & 0,96 & - \\
\hline 22 & 435 & 414 & 21 & 4 & 88 & 462 & 87,69 & 5,27 & $2^{\mathrm{a}}$ ordem \\
\hline 23 & 414 & 409 & 5 & 4 & 92 & 115 & 87,69 & 1,31 & - \\
\hline 24 & 409 & 402 & 7 & 4 & 96 & 168 & 87,69 & 1,92 & - \\
\hline 25 & 402 & 383 & 19 & 4 & 100 & 475 & 87,69 & 5,42 & $2^{\mathrm{a}}$ ordem \\
\hline 26 & 383 & 363 & 20 & 4 & 104 & 520 & 87,69 & 5,93 & $2^{\mathrm{a}}$ ordem \\
\hline 27 & 363 & 352 & 11 & 4 & 108 & 297 & 87,69 & 3,39 & $2^{\mathrm{a}}$ ordem \\
\hline 28 & 352 & 342 & 10 & 4 & 112 & 280 & 87,69 & 3,19 & $2^{\mathrm{a}}$ ordem \\
\hline 29 & 342 & 327 & 15 & 4 & 116 & 435 & 87,69 & 4,96 & $2^{\mathrm{a}}$ ordem \\
\hline 30 & 327 & 317 & 10 & 4 & 120 & 300 & 87,69 & 3,42 & $2^{\mathrm{a}}$ ordem \\
\hline 31 & 317 & 312 & 5 & 4 & 124 & 155 & 87,69 & 1,77 & - \\
\hline 32 & 312 & 308 & 4 & 4 & 128 & 128 & 87,69 & 1,46 & - \\
\hline 33 & 308 & 306 & 2 & 4 & 132 & 66 & 87,69 & 0,75 & - \\
\hline 34 & 306 & 291 & 15 & 4 & 136 & 510 & 87,69 & 5,82 & $2^{\mathrm{a}}$ ordem \\
\hline 35 & 291 & 280 & 11 & 4 & 140 & 385 & 87,69 & 4,39 & $2^{\mathrm{a}}$ ordem \\
\hline 36 & 280 & 277 & 3 & 4 & 144 & 108 & 87,69 & 1,23 & - \\
\hline 37 & 277 & 273 & 4 & 4 & 148 & 148 & 87,69 & 1,69 & - \\
\hline 38 & 273 & 263 & 10 & 4 & 152 & 380 & 87,69 & 4,33 & $2^{\mathrm{a}}$ ordem \\
\hline 39 & 263 & 261 & 2 & 4 & 156 & 78 & 87,69 & 0,89 & - \\
\hline 40 & 261 & 241 & 20 & 4 & 160 & 800 & 87,69 & 9,12 & $2^{\mathrm{a}}$ ordem \\
\hline
\end{tabular}


Silva et al.: Uso do índice RDE para determinação de anomalias de drenagem...

\begin{tabular}{l|l|l|l|l|l|l|l|l|l}
\hline 41 & 241 & 217 & 24 & 4 & 164 & 984 & 87,69 & 11,22 & $1^{\mathrm{a}}$ ordem \\
\hline 42 & 217 & 212 & 5 & 4 & 168 & 210 & 87,69 & 2,39 & $2^{\mathrm{a}}$ ordem \\
\hline 43 & 212 & 186 & 26 & 4 & 172 & 1118 & 87,69 & 12,75 & $1^{\mathrm{a}}$ ordem \\
\hline 44 & 186 & 170 & 16 & 4 & 176 & 704 & 87,69 & 8,03 & $2^{\mathrm{a}}$ ordem \\
\hline 45 & 170 & 159 & 11 & 4 & 180 & 495 & 87,69 & 5,64 & $2^{\mathrm{a}}$ ordem \\
\hline 46 & 159 & 140 & 19 & 4 & 184 & 874 & 87,69 & 9,97 & $2^{\mathrm{a}}$ ordem \\
\hline 47 & 140 & 134 & 6 & 4 & 188 & 282 & 87,69 & 3,22 & $2^{\mathrm{a}}$ ordem \\
\hline 48 & 134 & 134 & 0 & 4 & 192 & 0 & 87,69 & 0 & - \\
\hline 49 & 134 & 133 & 1 & 4 & 196 & 49 & 87,69 & 0,56 & - \\
\hline 50 & 133 & 130 & 3 & 4 & 200 & 150 & 87,69 & 1,71 & - \\
\hline 51 & 130 & 127 & 3 & 4 & 204 & 153 & 87,69 & 1,74 & - \\
\hline 52 & 127 & 118 & 9 & 4 & 208 & 468 & 87,69 & 5,34 & $2^{\mathrm{a}}$ ordem \\
\hline 53 & 118 & 99 & 19 & 4 & 212 & 1007 & 87,69 & 11,48 & $1^{\mathrm{a}}$ ordem \\
\hline 54 & 99 & 93 & 6 & 4 & 216 & 324 & 87,69 & 3,69 & $2^{\mathrm{a}}$ ordem \\
\hline 55 & 93 & 85 & 8 & 4 & 220 & 440 & 87,69 & 5,02 & $2^{\mathrm{a}}$ ordem \\
\hline 56 & 85 & 82 & 3 & 4 & 224 & 168 & 87,69 & 1,92 & - \\
\hline 57 & 82 & 80 & 2 & 4 & 228 & 114 & 87,69 & 1,30 & - \\
\hline 59 & 80 & 77 & 3 & 4 & 232 & 174 & 87,69 & 1,98 & - \\
\hline 60 & 77 & 70 & 7 & 4 & 236 & 413 & 87,69 & 4,71 & $2^{\mathrm{a}}$ ordem \\
\hline 61 & 62 & 62 & 8 & 4 & 240 & 480 & 87,69 & 5,47 & $2^{\mathrm{a}}$ ordem \\
\hline 62 & 56 & 53 & 3 & 4 & 248 & 186 & 87,69 & 2,12 & $2^{\mathrm{a}}$ ordem \\
\hline 63 & 53 & 49 & 4 & 4 & 252 & 252 & 87,69 & 2,87 & $2^{\mathrm{a}}$ ordem \\
\hline 64 & 49 & 45 & 4 & 4 & 256 & 256 & 87,69 & 2,92 & $2^{\mathrm{a}}$ ordem \\
\hline 65 & 45 & 38 & 7 & 4 & 260 & 455 & 87,69 & 5,19 & $2^{\mathrm{a}}$ ordem \\
\hline 66 & 38 & 31 & 7 & 4 & 264 & 462 & 87,69 & 5,27 & $2^{\mathrm{a}}$ ordem \\
\hline 67 & 31 & 27 & 4 & 4 & 268 & 268 & 87,69 & 3,06 & $2^{\mathrm{a}}$ ordem \\
\hline 68 & 27 & 16 & 11 & 4 & 272 & 748 & 87,69 & 8,53 & $2^{\mathrm{a}}$ ordem \\
\hline 69 & 16 & 12 & 4 & 4 & 276 & 276 & 87,69 & 3,15 & $2^{\mathrm{a}}$ ordem \\
\hline 70 & 12 & 8 & 4 & 4 & 280 & 280 & 87,69 & 3,19 & $2^{\mathrm{a}}$ ordem \\
\hline 71 & 8 & 7 & 1 & 4 & 284 & 71 & 87,69 & 0,81 & - \\
\hline 72 & 7 & 5 & 2 & 4 & 288 & 144 & 87,69 & 1,64 & - \\
\hline 73 & 5 & 3 & 2 & 4 & 292 & 146 & 87,69 & 1,66 & - \\
\hline 74 & 3 & 0 & 3 & 4,9 & 296,9 & 181,78 & 87,69 & 2,07 & $2^{\mathrm{a}}$ ordem \\
\hline
\end{tabular}

De acordo com a tabela acima o perfil longitudinal do Rio Capibaribe possui 36 trechos em equilíbrio $(48,65 \%)$, 35 trechos com anomalias de $2^{\text {a }}$ ordem $(47,3 \%)$ e apenas 3 trechos com anomalias de $1^{\underline{a}}$ ordem $(4,05 \%)$. Ainda de acordo com a tabela acima, verifica-se que 14 dos trechos com anomalias de $2^{a}$ ordem (aproximadamente $19 \%$ do perfil do Rio Capibaribe) apresentam índices RDE entre os limiares 2 a 3,5, ou seja, apresentam os desajustes mais suaves e relativamente próximos do equilíbrio. Dessa forma, considerando os 36 trechos descritos pela literatura como equilibrados e de forma ponderada considerando os trechos entre os limiares 2 e 3,5 como relativamente próximos do equilíbrio, pode-se afirmar que $67,57 \%$ do perfil longitudinal do Rio Capibaribe encontra-se em equilíbrio de drenagem ou relativamente próximo desse equilíbrio.

A figura 5 resume os valores do índice RDE calculados ao longo do curso principal da bacia hidrográfica do Rio Capibaribe (PE). 
Silva et al.: Uso do índice RDE para determinação de anomalias de drenagem...

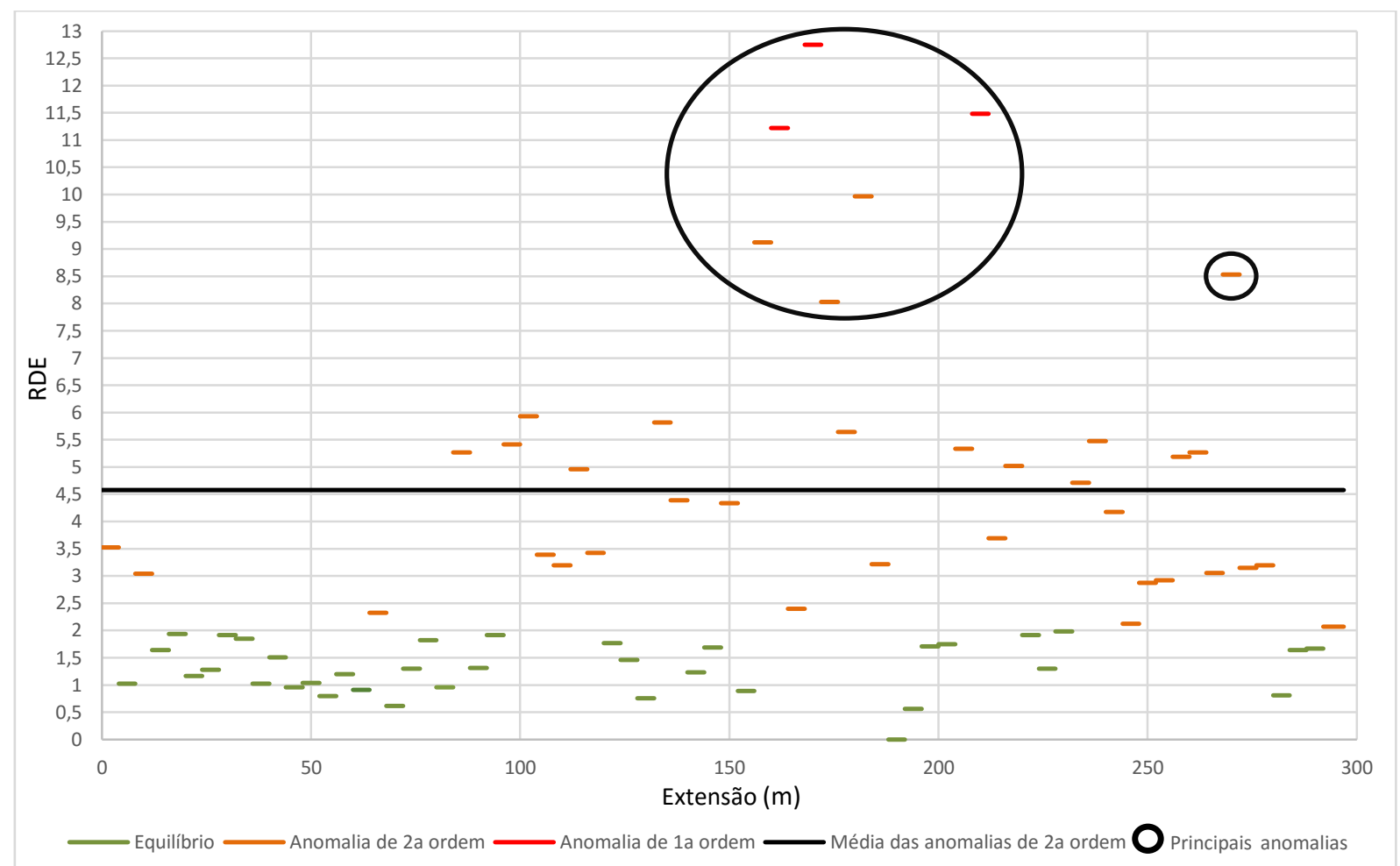

Figura 5 - Resumos dos valores de índice RDE ao longo do percurso do rio Capibaribe

Fonte: Google Earth (dados). Adaptado em Microsoft Excel 2013

O índice RDE médio dos trechos que apresentaram anomalias de $2^{\text {a }}$ ordem foi de 4,58 onde 19 dos 35 trechos possuem valores abaixo dessa média enquanto os desvios padrão e médio foram, respectivamente, 1,96 e 1,51. Além disso, os índices RDEs dos 3 trechos com anomalias de $1^{\text {a }}$ ordem, ou seja, aqueles que representam as alterações mais significativas em um perfil, pouco divergiram em relação ao limiar superior dos trechos com anomalias de $2^{\text {a }}$ ordem, apresentando nos trechos 41,43,53, respectivamente, índice RDEs iguais a 11,22, 12,75 e 11,48. Através da figura 5 percebe-se que o Rio Capibaribe apresentou poucos valores de índice RDE acentuados, além disso, verifica-se que os maiores valores de índices RDE concentram-se entre os quilômetros 156 e 212, também verifica-se índice RDE acentuado no trecho 68 entre os quilômetros 268 e 272 do curso principal do rio. Dessa forma, o cálculo do índice RDE sugere que o perfil longitudinal do rio Capibaribe em sua totalidade encontra-se relativamente equilibrado.

\subsection{Anomalias de drenagem}

A figura 6 apresenta o rio principal da bacia do Rio Capibaribe, assim como os trechos com anomalias de drenagem, obtidos de acordo com os valores de RDE calculados, conforme sugerido por Etchebehere (2000 apud Melo et al 2009). 


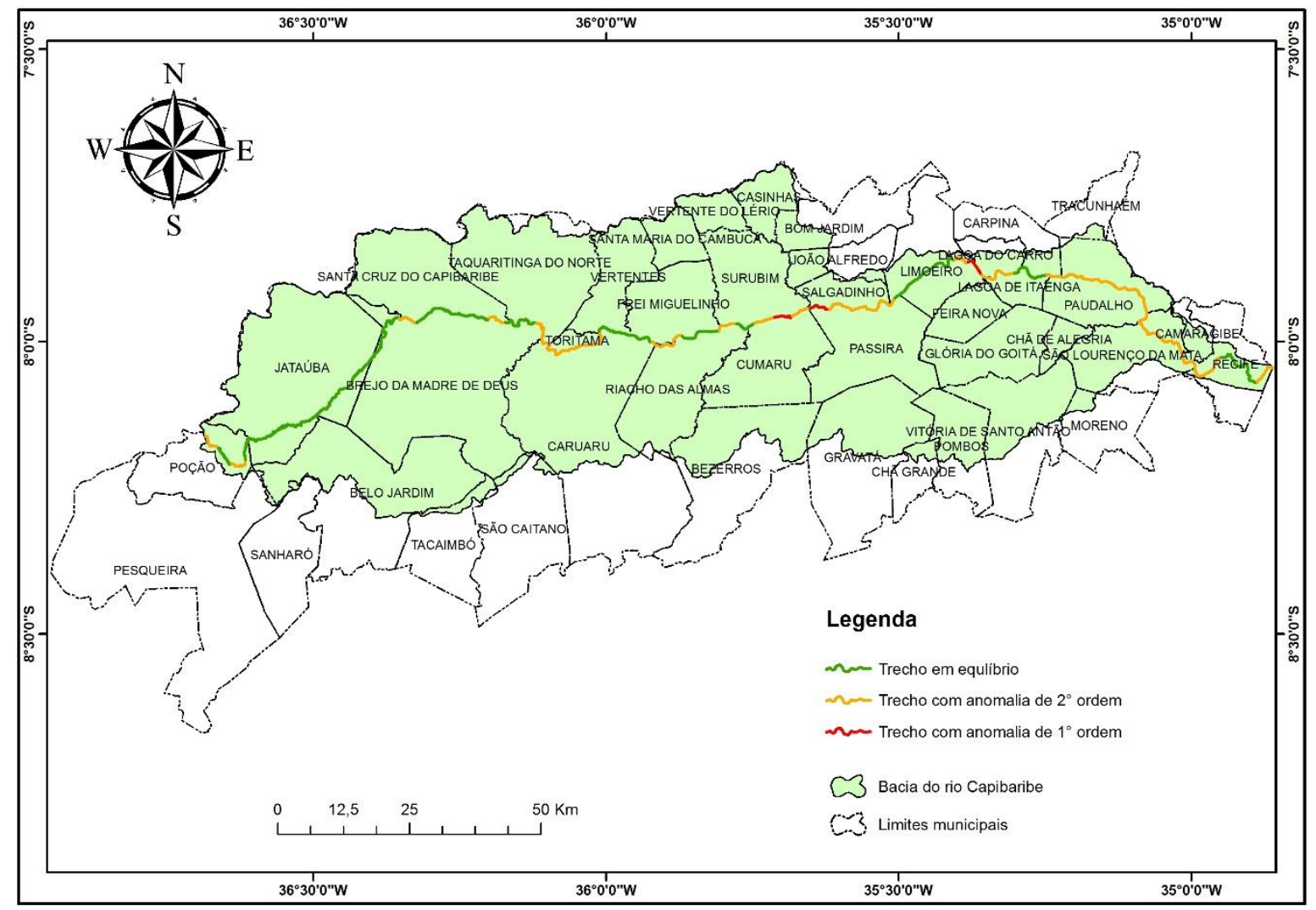

Figura 6 - Curso principal do rio Capibaribe com identificação das anomalias de drenagem

Fonte: Cartas SRTM EMBRAPA (Brasil em Relevo), Base Cartográfica IBGE, Google Earth. Adaptado por Silva, R. N. em ArcGis

Observa-se, entre outros, que o alto curso do Rio Capibaribe, em sua maior parte, encontra-se em equilíbrio, apresentando pequenos trechos com anomalias de $2^{a}$ ordem. Observa-se ainda, que em seu médio curso o Capibaribe torna-se predominantemente anômalo, apresentando em sua maior parte anomalias de $2^{\text {a }}$ ordem, que inicialmente alternam-se com trechos em equilíbrio até a divisa dos municípios de Cumaru e Surubim e a partir daí alternam-se com duas anomalias de $1^{\text {a }}$ ordem até encontrar os limites do município de Limoeiro. Em seu baixo curso o Rio Capibaribe também possui a maior parte de seu percurso com anomalias de $2^{\mathrm{a}}$ ordem. Em boa parte dos municípios de Limoeiro e Recife além de um pequeno trecho na divisa entre os municípios de Carpina e Lagoa do Itaenga o rio encontra-se em equilíbrio de drenagem, ainda em seu baixo curso, apresenta uma anomalia de $1^{\text {a }}$ ordem na divisa entre os municípios de Limoeiro e Lagoa do Carro. As anomalias de drenagem mais significativas apresentadas ao longo do percurso do Rio Capibaribe concentram-se entre a divisa dos municípios de Cumaru e Surubim e a divisa dos municípios de Limoeiro e lagoa do Carro.

\section{Conclusões}

O uso de imagens de satélite, mais precisamente do programa Google Earth permitiu a delimitação do curso do rio, indicação de pontos demarcatórios dos trechos correspondentes a todo curso do Rio Capibaribe e a construção do seu perfil longitudinal.

Nos trechos compreendidos, aproximadamente, entre os quilômetros 100 e 150, 150 e 200 e 200 e 250 do perfil longitudinal observa-se uma geometria atípica do perfil longitudinal, visto que a literatura indica que em um perfil típico a declividade deve diminuir no sentido da foz.

De acordo com os valores do índice RDE calculados nesse trabalho, e seus valores de referência apresentados por Etchebehere (2000 apud Melo et al 2009), o Rio Capibaribe encontra-se em equilíbrio de drenagem em boa parte de seu percurso, apresentando ainda quantia significativa de anomalias de 
$2^{\underline{a}}$ ordem e 3 anomalias de $1^{\underline{a}}$ ordem. Tais anomalias podem estar associadas a movimentos neotectônicos, resistência do substrato rochoso ou ao transporte de sedimento, relacionado por sua vez, a fatores antrópicos como desmatamento da mata ciliar, barramentos no curso do rio, confluência com rios tributários, etc. A associação das anomalias observadas nesse trabalho com tais fatores no Rio Capibaribe serão ainda investigadas em futuras pesquisas.

\section{Agradecimentos}

A Universidade de Pernambuco pela concessão de bolsa de Iniciação Científica através do seu Programa de Fortalecimento Acadêmico (PFA) ao primeiro autor deste trabalho.

\section{Referências}

AGÊNCIA PERNAMBUCANA DE ÁGUAS E CLIMAS (APAC). Bacia hidrográfica do rio Capibaribe. Disponível em: <http://www.apac.pe.gov.br/pagina.php?page_id=5\&subpage_id=14> acesso em: out. 2014.

ANDRADE, M. C. O. Pernambuco e o trópico. Revista do ieb, São Paulo, n. 45 p. 11-20, 2007. Disponível em: <http://www.ieb.usp.br/publicacoes/doc/rieb45_site_1322178209.pdf> Acesso em: fev. 2015.

AMARAL, C. B.; ROSALEN, D. L. Avaliação entre diferentes métodos para determinação da declividade. In: XXI CONGRESSO DE INICIAÇÃO CIENTÍFICA DA UNESP, São José do Rio Preto, UNESP, 2009.

CHRISTOFOLETTI, A. Geomorfologia. São Paulo, Edgard Blücher, 2a edição, 1980.

ETCEBEHERE, M. L. C.; SAAD, A. R. Relação declividade / extensão de curso (RDE) aplicada à detecção de deformações neotectônicas regionais na bacia hidrográfica do Rio do Peixe, SP. In: SIMPÓSIO DE GEOLOGIA DO SUDESTE, São Pedro, 1999, p. 93.

ETCHEBEHERE, M. L. C.; SAAD, A. R.; PERINOTTO, J. A. J.; FULFARO, V. J. Aplicação do Índice "Relação Declividade-Extensão - RDE" na Bacia do Rio do Peixe (SP) para detecção de deformações neotectônicas. Revista do Instituto de Geociências: Série Científica - USP, São Paulo,v. 4, n. 2, p. 43-56, 2004.

GUEDES, I. C. Análise de perfis longitudinais de drenagens da bacia do rio Santo Anastácio (SP) para detecção de possíveis deformações neotectônicas. Revista UnG - Geociências v.5, n.1, 2006.

HACK, J. T. Stream-profile analysis and stream-gradient index. Journal of Research of the U. S. Geological Survey - USGS, v. 1, n.4, p. 421-429, 1973. Disponível em: <http:/pubs.usgs.gov/journal/1973/vol1issue4/report.pdf> Acesso em: fev. 2015. 
Silva et al.: Uso do índice RDE para determinação de anomalias de drenagem...

LIMA, A. G. Índice de gradiente de canal: significados e diretrizes para aplicação. Brazilian Geographical Journal: Geosciences and Humanities research medium - UFU, v.4, p. 680-692, 2013.

MELO, O. A. G., FUJITA, R. H., SANTOS, M. L, F. Análise do perfil longitudinal do Rio Baiano -Assis Chateaubriand - PR a partir da aplicação do índice de gradiente (RDE). In: SIMPÓSIO BRASILEIRO DE GEOGRAFIA FÍSICA APLICADA, 13, 2009. Viçosa (MG).

MELO, A. G.; GOLDFARB, M. C. Contribuição para modelagem de perfil longitudinal: bacia do rio Una (PE) In: CONGRESSO DE MATEMÁTICA APLICADA E COMPUTACIONAL, 2012, Natal (RN), p. 109-111.

MIRANDA, E. E. de; (Coord.). Brasil em Relevo. Campinas: Embrapa Monitoramento por Satélite, 2005. Disponível em: <http://www.relevobr.cnpm.embrapa.br>. Acesso em: 4 jun. 2015.

NERY, C. V. M. Uso de imagens do Satélite CBERS 2B para detecção de áreas desmatadas no norte de Minas Gerais. In: SIMPÓSIO BRASILEIRO DE CIÊNCIAS GEODÉSICAS E TECNOLOGIAS DA GEOINFORMAÇÃO , 3., 2010, Recife (PE).

RODRIGUES, S. K.; SUGUIO, K, F. Gradientes hidráulicos das drenagens de 2a ordem: uma contribuição para os estudos de neotectônica da "Volta Grande" do rio Xingu, Altamira-PA. In: CONGRESSO BRASILEIRO DE GEOLOGIA, 1992, São Paulo (SP), p. 598-600.

SANTONI, G.; ETCHEBEHERE, M. L. C.; SAAD, A. R.; STEIN, D. P. Information theory and an extension of the maximum likelihood principle. In: ENCONTRO DE PESQUISA E JORNADA DE INICIAÇÃO CIENTÍFICA UNG, 2004, Guarulhos (SP).

SECRETARIA DE RECURSOS HÍDRICOS. Plano hidroambiental da bacia hidrográfica do rio capibaribe. TOMO I - Diagnóstico Hidroambiental, vol. 1. Projetos técnicos, Recife, 2010.

SILVA, L.A.; NAZARENO, N.R.X. Análise do padrão de exatidão cartográfica da imagem do Google Earth tendo como área de estudo a imagem da cidade de Goiânia. In: SIMPÓSIO BRASILEIRO DE SENSORIAMENTO REMOTO, 14., 2009, Natal (RN), p. 1723-1730.

SNOW, R S.; SLINGERLAND, R. L. Mathematical modeling of graded rivers profiles. Journal of Geology, v. 95, n. 1, p. 15-33, 1987.

SOUZA, R. B.; SOUZA, J. B.; GOLDFARB, M. C. Determinação e análise do perfil longitudinal do rio Una (PE). In: SIMPÓSIO BRASILEIRO DE RECURSOS HÍDRICOS, 19, 2011, Maceió (AL).

SOUZA, W. L. S.; Produção de sedimentos na bacia hidrográfica do rio Capibaribe para a zona costeira da região metropolitana do Recife. Dissertação (Mestrado em Ciência do Solo). 
Silva et al.: Uso do índice RDE para determinação de anomalias de drenagem...

Pernambuco: Universidade Federal Rural de Pernambuco, 2011. Disponível em: $<$ http://ufrpe.br/pgs/portal/files/dissertacoes/2011/WagnerLuizdaSilvaSouza.pdf $>$ Acesso em: Out. 2014.

ZANCOPÉ, M. H. C. PEREZ FILHO, A. CARPI JÚNIOR, S. Anomalias no perfil longitudinal e migração dos meandros do rio Mogi Guaçu. Revista Brasileira de Geomorfologia, v. 10, n. 1, 2009. 